\title{
REFLETINDO SOBRE O ENSINO JURÍDICO NO MESTRADO EM DIREITO DA REGULAÇÃO
}

\section{REFLECTING ON THE LEGAL EDUCATION IN MASTER IN REGULATORY LAW}

ReSUMO: A FGV, diferentemente do que muitos pensam, e em que pese sua missão de contribuir com "bens públicos", sob a ótica econômica, para o desenvolvimento nacional, é uma instituição privada. Foi criada em 1944 com o objetivo de ser um centro de excelência voltado para o desenvolvimento socioeconômico do Brasil. O foco, na ocasião, era a economia, a administração pública e de empresas. A missão final da FGV era (e ainda é) contribuir para o desenvolvimento socioeconômico do país, para a melhoria dos padrões éticos nacionais, para uma governança responsável e compartilhada e para a inserção do Brasil no cenário internacional. Como decorrência da crise de financiamento do Estado e do processo de redemocratização dos anos 1980, o histórico modelo intervencionista brasileiro, fortemente ancorado na atuação direta do Estado sobre a economia, cedeu espaço a um modelo temperado, em que o poder público passa a atuar principalmente por meio da intervenção indireta sobre os mercados, através de normatização, fomento e fiscalização: regulação. Assim, a criação do mestrado acadêmico em Direito da Regulação mostrou-se um caminho natural. O presente texto visa compartilhar com os leitores o registro de minha experiência docente e de coordenação do mestrado em direito da regulação, da Fundação Getúlio Vargas - FGV.

Palavras-Chave: Direito regulatório; Ensino jurídico; Pesquisa jurídica.

Abstract: FGV, unlike many think, and despite its mission to contribute "public goods", from the economic point of view, for national development, is a private

${ }_{1}$ Diretor, Professor Pesquisador Titular de Direito Administrativo da FGV DIREITO RIO. E-mail: sergio.guerra@fgv.br 
institution. It was created in 1944 with the aim of being a center of excellence focused on the socioeconomic development of Brazil. The focus, at the time, was economy, public administration and business. The final mission of FGV was (and still is) to contribute to the socioeconomic development of the country, to the improvement of national ethical standards, to responsible and shared governance and to Brazil's insertion in the international arena. As a result of the state financing crisis and the 1980s redemocratization process, the historical Brazilian interventionist model, strongly anchored in the State's direct action on the economy, gave way to a temperate model in which the public power began to act mainly through indirect intervention on the markets, through regulation, promotion and supervision: regulatory law. Thus, the creation of the academic master's degree in Regulatory Law has proved to be a natural path. The present text aims to share with the readers the record of my teaching experience and coordination of the master's degree in Regulatory Law, of the Fundação Getúlio Vargas - FGV.

PAlAVRAS-ChAVe: Regulatory law; Legal education; Legal research.

\section{INTRODUÇÃO}

O presente texto visa compartilhar com os leitores o registro de minha experiência docente e de coordenação do mestrado em direito da regulação, da Fundação Getúlio Vargas - FGV. ${ }^{2}$

A FGV, diferentemente do que muitos pensam, e em que pese sua missão de contribuir com "bens públicos", sob a ótica econômica, para o desenvolvimento nacional, é uma instituição privada. Não tem fins lucrativos, tendo sido criada em 1944 com o objetivo de ser um centro de excelência voltado para o desenvolvimento socioeconômico do Brasil. O foco, na ocasião, era a economia, a administração pública e de empresas.

Com mais de 70 anos de existência, a FGV consolidou-se como um centro de excelência acadêmica, com intensa, marcante e extensa produção intelectual. Sua missão institucional é avançar as fronteiras do conhecimento na área das ciências sociais e afins, produzindo e transmitindo ideias, dados e informações, além de conservá-los e sistematizá-los.

2 Parte das informações que compõem o presente texto foi submetida à Coordenação de Aperfeiçoamento de Pessoal de Nível Superior (Capes), fundação do Ministério da Educação (MEC), com a participação do Professor Doutor Fernando Leal, docente e atual coordenador do Mestrado em Direito da Regulação. 
A missão final da FGV é contribuir para o desenvolvimento socioeconômico do país, para a melhoria dos padrões éticos nacionais, para uma governança responsável e compartilhada e para a inserção do Brasil no cenário internacional.

A FGV surgiu no contexto em que Getúlio Vargas, visando burocratizar a administração pública, criou o Departamento de Administração e Serviço Público DASP, que, por sua vez, comandou mudanças significativas no funcionalismo estatal. ${ }^{3}$ Foi com Maurício Nabuco e Luiz Simões Lopes que a racionalização foi instituída na máquina pública, estruturada por meio de carreiras burocráticas na tentativa de serem preenchidas por concurso público. A ideia era a de modernizar a burocracia no âmbito da política e do aparato administrativo do Estado Novo. ${ }^{4}$

Diante das novas ativid ades assumidas pelo governo, a missão do DASP era formar quadros técnicos que deveriam ser capazes de dinamizar a máquina pública. Segundo Frederico Lustosa da Costa, ${ }^{5}$ o DASP foi efetivamente organizado em 1938, com a missão de definir e executar a política para o pessoal civil, inclusive a admissão mediante concurso público e a capacitação técnica do funcionalismo, promover a racionalização de métodos no serviço público e elaborar o orçamento da União.

Essa primeira experiência de reforma de largo alcance inspirava-se no modelo weberiano de burocracia e tomava como principal referência a organização do serviço norte-americano.

3 “O DASP representou a concretização desses princípios, já que se tornou a grande agência de modernização administrativa, encarregada de implementar mudanças, elaborar orçamentos, recrutar e selecionar servidores, treinar o pessoal, racionalizar e normatizar as aquisições e contratos e a gestão do estoque de material. O DASP foi relativamente bem-sucedido até o início da redemocratização em 1945, quando houve uma série de nomeações sem concurso público para vários organismos públicos. A liberdade concedida às empresas públicas, cujas normas de admissão regulamentadas pelos seus próprios estatutos tornavam facultativa a realização de concursos foi em parte responsável por tais acontecimentos." COSTA, Frederico Lustosa da. Brasil: 200 anos de Estado; 200 anos de administração pública; 200 anos de reformas. Revista de Administração Pública, Rio de Janeiro 42(5):829-74, set/out. 2008.p. 846.

${ }_{4}$ Nome do regime político, centralizado e autoritário, surgido com a promulgação da Constituição Federal de 1937, que apresentou o seguinte texto inicial: “ATENDENDO às legitimas aspirações do povo brasileiro à paz política e social, profundamente perturbada por conhecidos fatores de desordem, resultantes da crescente a gravação dos dissídios partidários, que, uma, notória propaganda demagógica procura desnaturar em luta de classes, e da extremação, de conflitos ideológicos, tendentes, pelo seu desenvolvimento natural, resolver-se em termos de violência, colocando a Nação sob a funesta iminência da guerra civil; ATENDENDO ao estado de apreensão criado no País pela infiltração comunista, que se torna dia a dia mais extensa e mais profunda, exigindo remédios, de caráter radical e permanente; ATENDENDO a que, sob as instituições anteriores, não dispunha, o Estado de meios normais de preservação e de defesa da paz, da segurança e do bem-estar do povo; Com o apoio das forças armadas e cedendo às inspirações da opinião nacional, umas e outras justificadamente apreensivas diante dos perigos que ameaçam a nossa unidade e da rapidez com que se vem processando a decomposição das nossas instituições civis e políticas; Resolve assegurar à Nação a sua unidade, o respeito à sua honra e à sua independência, e ao povo brasileiro, sob um regime de paz política e social, as condições necessárias à sua segurança, ao seu bem-estar e à sua prosperidade, decretando a seguinte Constituição, que se cumprirá desde hoje em todo o Pais: ..."

${ }_{5}^{5}$ COSTA, Frederico Lustosa da. Reforma do estado e contexto brasileiro: crítica do paradigma gerencialista. Rio de Janeiro: FGV, 2010. p. 97. 
Tudo começa, naquela nação do norte, com a crise decorrente da Grande Depressão (Great Depression), ocorrida na década de 1930, que acabou por levar à criação de muitas agências governamentais. Em que pese a existência de entes reguladores desde o século XVIII, foi no Governo do Presidente Franklin D. Roosevelt, primo de Theodore Roosevelt, sob a forma de um programa conhecido como New Deal, em que o Poder Executivo e o Congresso estruturaram a máquina estatal para enfrentar os enormes e complexos problemas sociais e econômicos que o país enfrentava. ${ }^{6}$

O programa resultou na estruturação de uma burocracia federal, bem diferente do antigo modelo denominado spoil system, em que os cargos públicos eram preenchidos pelos partidos políticos vencedores das eleições. Roosevelt criou uma Comissão (Committe on Administrative Management), que ficou popularmente conhecida como Brownlow Committee, por ter sido comandada por Louis Brownlow.

O trabalho consistia em analisar a organização do poder executivo e sugerir soluções para grandes problemas que afetavam a governança estatal.

O relatório Brownlow, concluído em 1937, fez diversas recomendações, incluindo a criação de um órgão (The Executive Office of the President - EOP), que reunisse as atividades do poder executivo, tais como orçamento, eficiência, pessoal e planejamento.

O Congresso rejeitou algumas propostas contidas no relatório Brownlow, mas aprovou a criação do EOP, por meio do Reorganization Act de abril de 1939. O principal benefício dessa inovação, trazida pelo relatório Brownlow, consistiu na estruturação de um órgão de apoio direto da presidência da república. Lançou as bases para a estrutura administrativa básica, que permitiria o gerenciamento das inúmeras e diversas atividades afetas ao poder executivo.

Nesse contexto, destaque-se no Brasil a criação da Fundação Getulio Vargas, também sob a inspiração de Luís Simões Lopes, então presidente do DASP. A ideia foi criar uma fundação dedicada ao estudo e ao ensino dos problemas de administração. Sua criação data de 20 de dezembro de 1944, com recursos financeiros de órgãos públicos e de empresas privadas.

A FGV começou atuando na área de economia em 1946, sob a liderança de Eugênio Gudin. O Instituto Brasileiro de Economia (IBRE) foi criado em 1951, a Escola Brasileira de Administração Pública (EBAP), hoje Escola Brasileira de Administração Pública e Empresas (EBAPE), em 1952, no Rio de Janeiro. A Escola de Administração de Empresas (EAESP) foi criada em 1954, em São Paulo. Depois, vieram a Escola de PósGraduação em Economia (EPGE), em 1966 e o Centro de Pesquisa e Documentação de História Contemporânea do Brasil (CPDOC), em 1973. Em 2002 foram criadas as Escola de Economia de São Paulo (EESP), Escolas de Direito de São Paulo (DIREITO SP) e do Rio de Janeiro (DIREITO RIO), em 2002. A FGV/EMAp - Escola de Matemática Aplicada - foi criada em 2011 para o desenvolvimento de uma matemática contemporânea, adaptada aos desafios da era da informação e do conhecimento.

${ }^{6}$ Cf. MCCRAW, Thomas K., et al. Prophets of regulation: Charles Francis, Adams Louis D. Brandeis, James M. Landis, Alfred E. Kahn. Massachussets: Harvard, 1984. p.152. 
Tanto o DASP quanto a FGV são considerados importantes atores na estruturação do princípio do mérito profissional no âmbito das carreiras de Estado ${ }^{7}$, sempre devendo destacar a forma de organização pública hierarquizada. ${ }^{8}$

Marca de pioneirismo e ousadia, a FGV inaugurou no Brasil a graduação e a PósGraduação stricto sensu em Administração Pública e Privada, bem como cursos de pósgraduação em Economia, Psicologia, Ciências Contábeis, Ciências Sociais e Educação. A FGV também contribuiu para as bases de uma economia bem fundamentada, a partir da elaboração do balanço de pagamento, das contas nacionais e dos índices econômicos. Iniciativas como essas ajudaram o profissional em busca de formação e até o cidadão comum a entenderem melhor o desempenho econômico e social brasileiro.

\section{A FGV DIREITO RIO}

A criação da Escola de Direito do Rio de Janeiro da FGV, em 2002, não se afastou dos objetivos centrais da FGV. A FGV Direito Rio foi criada com a tarefa desafiadora de inovar no ensino jurídico, na pesquisa, na didática e no currículo de um curso de Direito. Seu propósito maior era - e permanece sendo - contribuir para a formação de lideranças para pensar o Brasil em longo prazo.

Hoje, cerca de dezessete anos após a sua fundação, a Escola já pode ser considerada referência no país, de conteúdo e metodologia de ensino e de pesquisa. Para a realização de seus objetivos institucionais são desenvolvidas ações principalmente em duas frentes: (i) ensino, por meio do oferecimento de cursos de Direito nos níveis de graduação, pós-graduação (Lato e Stricto Sensu) e educação continuada, e (ii) pesquisa, por meio do desenvolvimento de projetos de pesquisa com a participação de discentes da graduação e da pós-graduação, docentes dos centros de pesquisa da FGV Direito Rio e de outras instituições parceiras.

A FGV Direito Rio inova ao optar por uma metodologia participativa, em que o aluno não é somente espectador, mas sujeito ativo na construção do conhecimento. Isso significa uma metodologia de ensino dinâmica, que privilegia o debate em vez das aulas puramente expositivas. Assim ocorre no chamado método socrático, base didática da Escola, que permite que os alunos sejam também avaliados por suas contribuições em sala de aula. Várias técnicas participativas são utilizadas, tais como o método de estudo e apresentação de casos concretos, dinâmicas de grupo, todas realizadas em um ambiente de interatividade entre aluno e professor em turmas com número limitado de alunos.

7 Conforme Plano Diretor da Reforma do Aparelho do Estado, disponível em http://www.planalto.gov.br/publi_04/COLECAO/PLANDI3.HTM.

8 O DASP, segundo Bianor Cavalcanti, foi um instrumento de exercício do poder central autoritário, embora comprometido com o projeto desenvolvimentista, não tendo, portanto, escapado das influências culturais condicionantes. CAVALCANTI. Bianor Scelza. O gerente equalizador: estratégias de gestão no setor público. Rio de Janeiro: Editora FGV, 2008. p. 46. 
É nesse ambiente de efervescência acadêmica, inovação no ensino do direito, preocupação com o aprimoramento das instituições nacionais e intenso diálogo internacional que se insere o programa de mestrado em direito da regulação da FGV Direito Rio.

\section{Mestrado eM DiReito da RegulaçÃo}

O programa de mestrado em Direito da Regulação revelou-se um caminho natural tendo em vista (i) a organização interna da FGV Direito Rio, que se estrutura em torno de quatro centros de pesquisa com agendas em grande parte voltadas ao fenômeno regulatório, (ii) a produção intelectual do seu corpo docente e (iii) os cursos, eventos e iniciativas de inserção social levados adiante na Escola de Direito da FGV desde o seu início.

O mestrado em Direito da Regulação tem por principal objetivo contribuir para o aprimoramento da pesquisa nacional na área regulatória, visando a ser uma referência no Brasil e no exterior na área. Para tanto, o programa pretende desenvolver estudos destinados à compreensão adequada dos diferentes aspectos por trás do exercício de atividades regulatórias e propor soluções para lidar com os problemas gerais e setoriais da regulação.

Além dos programas de graduação e pós-graduação em Direito oferecidos em âmbito nacional, a FGV Direito Rio dispõe de convênios com universidades nacionais e estrangeiras que possibilitam a seus docentes e discentes participarem de seminários, palestras e intercâmbios no exterior e em outras universidades nacionais. Dentre as instituições parceiras sobressaem-se a Harvard Law School, Yale Law School, Science Po Paris, New York University e a Universidade de Coimbra. Na mesma linha de expansão internacional da graduação, o mestrado em direito da regulação busca constantes parcerias no exterior, que sejam capazes de garantir o aumento do fluxo de docentes e discentes e o estabelecimento de projetos comuns de pesquisa. Busca expandir, assim, as fronteiras de sua atuação e contribuindo para que o programa se torne referência internacional em temas relacionados ao direito da regulação e à realidade regulatória brasileira.

As pesquisas da FGV Direito Rio, de acordo com sua natureza, vêm sendo desenvolvidas dentro dos Centros de Pesquisa, a saber: Centro de Pesquisas em Direito e Economia (CPDE) - criado em 2009, é um centro de estudos que tem por objetivo realizar pesquisas interdisciplinares nas áreas de interseção entre o Direito e a Economia, promovendo análises e discussões sobre os efeitos esperados de normas e decisões jurídicas sobre o comportamento dos agentes econômicos e o desenvolvimento socioeconômico do País. São membros efetivos do CPDE professores da Escola de Direito do Rio de Janeiro, que contam com a colaboração de professores da Escola de Direito de São Paulo (Direito SP) da Fundação Getúlio Vargas e das Escolas de Economia do Rio de Janeiro e de São Paulo, também da Fundação Getúlio Vargas. Completam a equipe estagiários graduandos em Direito pela FGV Direito Rio e Economia pela Escola Brasileira de Economia e Finanças da FGV Rio. Os 
pesquisadores associados do CPDE atuam em Grupos de Trabalho para o desenvolvimento de linhas de pesquisa acadêmica. Os resultados de seus estudos são divulgados por meio da publicação de artigos acadêmicos em periódicos renomados e matérias publicadas mensalmente na revista Conjuntura Econômica, produzida pelo Instituto Brasileiro de Economia (IBRE) da Fundação Getúlio Vargas. Além disso, o Centro procura propiciar a tradução e/ou revisão técnica de textos clássicos da literatura internacional nas áreas de direito e economia.

Centro de Justiça e Sociedade (CJUS) - criado em 2004, o CJUS tem a missão de produzir conhecimento sobre o papel institucional e o modo de funcionamento do Poder Judiciário e das outras instituições do sistema de justiça. As atividades do Centro são orientadas não somente para a produção de conhecimento, mas também para colaborar com a modernização do Judiciário e das instituições do sistema de justiça, assim como fomentar a pesquisa e o desenvolvimento das carreiras jurídicas na área pública. Neste sentido, o CJUS conta com o apoio de diversos tribunais, empresas e instituições do terceiro setor. O DNA do CJUS está ligado, desde o início, tanto à análise compreensiva e à visão transformadora do sistema de justiça, como ao municiamento dos membros desse sistema e de toda a sociedade civil com informações e propostas de melhoria dos indicadores relacionados à efetivação da justiça visando à consolidação da democracia no país. O Centro reúne pesquisadores dedicados ao estudo e discussão de temas ligados a: (i) modernização administrativa das instituições do sistema de justiça brasileiro (novas formas de gestão e novas práticas judiciais), (ii) acesso da sociedade aos serviços jurisdicionais e configuração de novas demandas de acesso à Justiça, (iii) redução de litigância e soluções alternativas na resolução de conflitos, (iv) políticas públicas e promoção de direitos sociais a partir do sistema de justiça, (v) relações entre Justiça, Política e Sociedade, e (vi) produção e sistematização de estatísticas sobre o sistema de justiça brasileiro. Além da realização de pesquisas, o centro visa difundir conhecimento e provocar discussões sobre desenho de pesquisa e utilização de metodologias empíricas de pesquisa no campo do Direito, voltados à compreensão, reforma e formulação de análises e diagnósticos sobre o Poder Judiciário brasileiro e as demais instituições que compõem o sistema de justiça.

Centro de Direito e Meio Ambiente (CDMA) - tem a missão institucional de produzir conhecimentos inovadores para aprimorar e consolidar cada vez mais o direito ambiental nacional e internacional, sob uma perspectiva aberta e interdisciplinar. Por meio de diversos instrumentos jurídicos, tais como o direito constitucional, administrativo, civil e internacional, busca-se aprimorar o direito ambiental para que ele se adéque à complexidade do regime constitucional brasileiro e das diferentes demandas e interesses que pautam as relações internacionais. Outras áreas do conhecimento como a economia e as ciências sociais estão diretamente ligadas às pesquisas do programa. O CDMA tem como foco estudar e promover a efetividade do direito ambiental. Para tanto, os métodos empíricos e a análise jurisprudencial são privilegiados para que os estudos sejam coerentes com a realidade. Além disso, parcerias com atores ligados a políticas ambientais são priorizadas. A sociedade civil organizada, o Ministério Público, o Poder Judiciário, a Defensoria Pública e o setor produtivo são parceiros potenciais do CDMA.

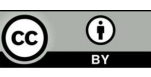


Centro de Tecnologia e Sociedade (CTS) - fundado em 2003, o CTS tem a missão institucional de estudar as implicações jurídicas, sociais e culturais advindas do avanço das tecnologias da informação e da comunicação. Suas atividades são desenvolvidas com foco na investigação acadêmica e na divulgação científica que possam impactar a formação de políticas públicas comprometidas com a democracia, os direitos fundamentais e a preservação do interesse público no progresso tecnológico. Suas pesquisas e publicações são conduzidas por pesquisadores com formação não apenas jurídica. A diversidade de especializações permite que os projetos contem com uma perspectiva multidisciplinar, abrangendo temas diversos e pouco usuais em centros de estudos jurídicos. O CTS mantém ampla interlocução com parceiros externos, dialogando com governo, sociedade civil, empresas e outras instituições de ensino. Por possuir experiência em processos de discussão legislativa por meio de plataformas digitais, participa ativamente na elaboração de projetos de lei e demais políticas públicas no Brasil e no exterior.

O Programa de Pós-Graduação stricto sensu em Direito da Regulação ajusta-se às políticas de pesquisa da FGV Direito Rio e aos objetivos de formação de pesquisadores de alto nível que estejam aptos a associar sólida base científica, adquirida no programa e nos projetos de pesquisa, para colaborar na solução das demandas nacionais e globais.

As relações entre os centros de pesquisa e o mestrado em direito da regulação tornam-se evidentes quando o foco recai sobre as suas duas linhas de pesquisa: Governança Regulatória; Instituições, Justiça e Economia; Intervenção e Estratégias Regulatórias.

As conexões entre os centros de pesquisa e o mestrado se revelam em duas perspectivas diferentes. De um lado, a concepção do programa de mestrado inspirouse nas partes das agendas de pesquisa dos centros que tocassem a área regulatória. Neste aspecto, o mestrado organizou-se, desde o início, de modo a aproveitar a estrutura de pesquisa existente na Escola. De outro, e em razão dessa conexão, o programa de mestrado influencia e é permanentemente influenciado pelas iniciativas e projetos de pesquisa desenvolvidos por docentes e discentes, de graduação e pósgraduação, nos centros da FGV Direito Rio.

Essa relação de mão-dupla potencializa a produção científica de qualidade no âmbito do mestrado e cria mais espaços de interação entre o mestrado e as áreas de pesquisa da FGV Direito Rio, o que permite que os alunos de graduação e pósgraduação possam se beneficiar rapidamente dos dados e reflexões presentes nos trabalhos dos professores vinculados ao programa.

\section{PRojeto de MESTRAdo ACADÊMico}

Como decorrência da crise de financiamento do Estado e do processo de redemocratização dos anos 1980, o histórico modelo intervencionista brasileiro, fortemente ancorado na atuação direta do Estado sobre a economia, cedeu espaço a um modelo temperado, em que o poder público passa a atuar principalmente por meio 
da intervenção indireta sobre os mercados, através de normatização, fomento e fiscalização.

Uma visão abrangente do Direito da Regulação inclui a disciplina jurídica dos valores essenciais compartilhados pela sociedade brasileira, tais como o direito à saúde, à educação, ao meio ambiente sustentável, ao acesso às novas tecnologias e ao sistema jurisdicional. Observa-se o aprofundamento das diversas formas de parcerias entre a Administração Pública, o mercado e a sociedade civil, requerendo maior reflexão acerca dos institutos e instituições necessários à boa regulação.

A criação do mestrado acadêmico em Direito da Regulação mostrou-se um caminho natural a ser seguido tanto em razão da importância do tema no contexto do país, assim como pelas pesquisas realizadas na FGV Direito Rio em setores regulatórios. Essas pesquisas foram importantes, primeiramente, para a idealização e, posteriormente, para a concretização do mestrado.

O interesse da Escola em direito da regulação pode ser notado, porém, não só no desenvolvimento de pesquisas relacionadas às diversas dimensões do tema, mas também pode ser observado no âmbito do ensino com a experiência bem-sucedida do LLM em Direito do Estado e da Regulação uma pós-graduação lato sensu, oferecida desde 2005.

Nesse cenário, a opção pela criação de um programa de mestrado na área de direito da regulação representou a formalização de um espaço para a produção, aprofundamento e divulgação de ideias que já inspiravam as áreas centrais da FGV Direito Rio. "Direito da regulação" e os múltiplos aspectos que tocam direta ou indiretamente a atividade regulatória são, no fundo, temas que estão presentes e orientam a agenda de pesquisa de professores e da própria instituição. Isso se torna evidente quando se adota uma perspectiva mais ampla sobre o fenômeno regulatório. Regulação pode ser definida como um conjunto de "técnicas administrativas consubstanciadas em normas destinadas à organização do sistema econômico ou que geram efeitos sobre o sistema econômico" ${ }^{9}$

Ademais, regulação também se refere (i) a um específico conjunto de regras destinado a realizar certos objetivos e a ser aplicado por uma instituição desenhada para atingir esses propósitos, (ii) a todas as ações estatais desenhadas para influenciar o comportamento social ou negocial ou (iii) todos os mecanismos que afetam comportamentos, independentemente de terem ou não origem estatal. ${ }^{10}$

Sob todas essas perspectivas, a atividade regulatória ganha contornos muito mais amplos, o que exige e, ao mesmo tempo, justifica perspectivas inter e multidisciplinares para que se possa compreender plenamente $\mathrm{o}$ fenômeno regulatório. É com esse propósito que o programa de mestrado em direito da regulação da FGV Direito Rio foi concebido e está estruturado para fomentar o desenvolvimento de pesquisas que enfrentem não apenas temas relacionados ao funcionamento de setores regulados e ao papel do Estado na implementação de mecanismos de incentivo

${ }_{9}$ MATTOS, Paulo. O novo estado regulador no Brasil. São Paulo: Singular, 2006, p. 33, nota 7.

${ }^{10}$ BALDWIN, Robert; CAVE, Martin; LODGE, Martin. Understanding Regulation. Theory, Strategy, and Practice. 2nd. Ed. Oxford: OUP, 2012, pp. 2-3. 
para orientar o comportamento de agentes econômicos de modo a possibilitar o alcance de resultados desejáveis e a impedir a ocorrência de resultados indesejáveis.

A riqueza da agenda regulatória também requer o enfrentamento de temas e problemas diversos, como os que dizem respeito (i) ao papel do Estado na economia, (ii) aos programas e limites constitucionais que afetam e deveriam influenciar o desempenho das atividades estatais, (iii) à tomada de decisão regulatória e à interpretação de normas, (iv) ao controle da atividade regulatória, (v) aos arranjos institucionais atuais e às alternativas de modelo regulatório, (vi) à compreensão das diversas formas de diálogo entre o direito e a economia, (vii) às relações entre incentivos regulatórios e o desempenho de atividades empresariais, (viii) às diversas formas de interação entre órgãos reguladores e outros poderes, (ix) à estrutura das normas que concretizam opções regulatórias, $(x)$ a dimensão política da regulação e a legitimidade democrática da ação regulatória, (xi) aos aspectos epistêmicos subjacentes a escolhas regulatórias e ao desenvolvimento de teorias sobre a intensidade de controle dessas escolhas, (xii) às estruturas de governança que favorecem a responsividade de agentes reguladores e regulados e (xiii) aos aspectos penais e tributários da regulação. Esses são apenas exemplos de assuntos que podem compor um programa de pesquisa ao mesmo tempo amplo e profundo sobre as inúmeras dimensões relacionadas à regulação.

$\mathrm{Na}$ parte referente à governança regulatória, merece registro que o modelo de agencificação nacional é uma reprodução (parcial) do padrão existente nos Estados Unidos da América. Enquanto, no Brasil, a primeira agência teve sua lei de criação editada em 1996,11 o modelo norte-americano surgiu em 1887, com a Interstate Commerce Commission - ICC). ${ }^{12}$ Para efeitos históricos, a ICC marca o início da implantação desse padrão burocrático na regulação de atividades econômicas, envolvendo o complexo sistema ferroviário que ultrapassava as fronteiras dos estados da federação.

Em que pese a ICC marcar o início dessa fase, vale registrar que já havia, nos Estados Unidos da América, intervenção estatal indireta sobre atividades econômicas desde meados do século XIX, com a regulação do transporte por barcos a vapor (steamboat inspectors). ${ }^{13}$

Diante das características dessas novas autarquias brasileiras, e se não há dúvidas de que o modelo de agencificação nacional está próximo ao sistema de agências reguladoras independentes dos Estados Unidos da América, ${ }^{14}$ justifica-se a realização

${ }^{11}$ Lei no 9.427, de 26 de dezembro de 1996, que institui a Agência Nacional de Energia Elétrica - ANEEL.

12 Para compreender o contexto em que foi criada a ICC, recomenda-se as seguintes obras: KOLKO, Gabriel. Railroads and regulations: 1877 - 1916. New York: The Norton Library, 1965. p. 45 ss, e FELLMETH, Robert. The interstate commerce omission. New York: Grossman Publishers, 1970.

${ }^{13}$ Conforme amplo levantamento histórico elaborado pelo Professor da Yale Law School, Jerry Mashaw, e constante da sua obra Creating the administrative constitution: the lost one hundred years of American administrative law. New Haven: Yale University Press, 2012, p. 314.

14 A estrutura detalhada do sistema regulatório norte-americano pode ser conferido em CASS, Ronald A. et al. Administrative law. 6a. ed. New York: Wolters Klumer Law \& Business, 2011. 
de pesquisas sobre o sesquicentenário modelo norte-americano, de viés progressista ${ }^{15}$, sob a ótica comparada.

Tendo passado por diversas fases durante a sua história republicana, o longevo modelo de agencificação estadunidense é muito rico, contendo elementos que podem contribuir no aclaramento de certas incompreensões sobre o padrão regulatório brasileiro.

\section{CARACTERÍSTICAS DO CORPO DOCENTE}

Visando enfrentar os temas antes apontados, adequadamente, o programa de Mestrado em Direito da Regulação reúne professores com formações distintas que podem contribuir para o desenvolvimento da pesquisa acadêmica na área de concentração. Essas formações passam pela economia, a ciência política, a teoria do direito, a teoria constitucional, a teoria do Estado, o direito da concorrência, o direito empresarial, o direito tributário, o direito penal, o direito ambiental e, naturalmente, o direito administrativo.

Todos esses conhecimentos convergem, no fundo, para que a formação discente e as pesquisas docentes contribuam para o enfrentamento, sob uma perspectiva inovadora, dos inúmeros problemas atuais e potenciais vinculados à atividade regulatória. Metodologicamente, por fim, o programa abre espaço para investigações empíricas, tanto quantitativas como qualitativas e estudos de direito comparado.

\section{LINHAS DE PESQUISA E ATIVIDADE DISCENTE}

A área de concentração em Direito da Regulação é composta por duas linhas de pesquisa de suma importância para o atual cenário de mudanças e de desenvolvimento do Estado Regulador Brasileiro: Governança Regulatória, Instituições, Justiça e Economia, Intervenção e Estratégias Regulatórias. Todas as

\footnotetext{
15 Susan Rose-Ackerman adverte que, para os progressistas, o moderno sistema estatal regulatório é o eixo do direito norte-americano: "For progressives, the modern regulatory-welfare state is at the heart of American Law." ROSE-ACKERMAN, Susan. Rethinking the progressive agenda: the reform of the American regulatory state. New York: The Free Press, 1992. p. 3. O movimento progressista ocorreu basicamente pela atuação da classe média e cidadãos localizados em áreas urbanas chocados com a corrupção e fraudes no campo político da virada do século XIX. A solução para esses problemas seria a criação de agências de modo que as decisões sobre o controle de determinadas atividades industriais fossem decididas por experts, de forma racional e livres das pressões partidárias. Cf. BERNSTEIN, Marver H. Regulating business by independent commission. 2. tir. New Jersey: Princeton University Press, 1955. p. 35. Sobre as críticas ao movimento progressista, ver a obra: EPSTEIN, Richard A. How progressives rewrote the constitution. Cato Institute: Washington, 2001. p. 52 ss. Esse autor é um dos maiores defensores da tese de retorno do papel estatal ao viés liberal clássico sobre a economia. Ver, ainda, do mesmo autor, EPSTEIN, Richard A. Why the modern administrative state is inconsistent with the rule of law. NYU Jornal of Law E Liberty, v. 3, 2006. p. 491-515.
} 
linhas, como exposto, abrangem as principais linhas de investigação da FGV Direito Rio, as áreas de atuação dos professores do programa e todos os aspectos da concepção ampla de regulação que inspira a construção e o funcionamento do programa.

A maturidade científica do corpo docente selecionado para o programa de Mestrado em Direito pode ser verificada pelos resultados apresentados na forma de artigos científicos, livros, organização de congressos nacionais e internacionais e apresentação de trabalhos em eventos. Ademais, a estrutura curricular proposta alinha-se diretamente à experiência e capacidade docentes e aos objetivos propugnados nos projetos de pesquisa em desenvolvimento e já concluídos.

O Programa em Direito da Regulação foi credenciado pela CAPES em março de 2013 e sua primeira turma teve início em 2014. Destaca-se pela sua proposta inovadora e pioneira, pois é o primeiro Mestrado em Direito da Regulação, com área de Concentração em Direito da Regulação a ser oferecido no Brasil. Além disso, auxilia no atendimento de demanda de formação de pesquisadores no Estado do Rio de Janeiro.

O programa de Mestrado conta com um programa de concessão de Bolsas de Estudos aos discentes que demonstrem, dentre outros critérios, a excelência acadêmica. São três modalidades de bolsas de estudos - quotas do PROSUP da CAPES, da FAPERJ para Programas emergentes, e recursos da própria FGV Direito Rio. O Mestrado em Direito da Regulação privilegia, ainda, os discentes que possam se dedicar integralmente às atividades para obtenção dos créditos acadêmicos formais, que abrangem tanto o cumprimento das disciplinas como para a participação em atividades supervisionadas, que compreendem os projetos de pesquisa, estágio de docência, participação em seminários de pesquisa e grupos de estudo.

Vale dizer que os docentes e discentes do programa de Mestrado em Direito da Regulação são permanentemente estimulados a publicarem, individual ou coletivamente, em meios de comunicação e periódicos especializados e a participarem de eventos, simpósios e congressos nacionais ou estrangeiros.

O programa de Mestrado faz parte da REDISCURSUS - Rede de Pesquisa em Direito, Instituições e Desenvolvimento criada com o objetivo de propor atividades de pesquisa e intercâmbio de docentes e discentes entre programas de pós-graduação stricto sensu membros. As linhas de pesquisa definidas para o desenvolvimento de pesquisas acadêmicas são: (i) Mundialização, Cultura e Novos Direitos - palavraschave: direitos humanos, governança, regionalismos e tecnologia, (ii) Direito, Desenvolvimento e Sustentabilidade - palavras-chave: desenvolvimento humano, políticas públicas, meio ambiente e risco, e (iii) Instituições e Desenvolvimento palavras-chave: direito e economia, direito e democracia, e desenhos institucionais.

\section{REFLEXÕES FINAIS}

A Constituição Federal de 1988 definiu, expressamente, os princípios a serem observados pelo Poder Legislativo e Poder Executivo na regulação econômica e social, cujos vetores, na primeira vertente, são a fiscalização, o incentivo e o planejamento não 
obrigatório para o setor privado. Ao Estado permitiu-se atuar diretamente mediante a exploração de atividade econômica quando necessária aos imperativos da segurança nacional ou relevante interesse coletivo, conforme definidos em lei.

A função de regulação não está detalhada na Constituição Federal. Por meio da regulação deve-se buscar a conformação da garantia de equilíbrio de um subsistema, por meio de mecanismos que garantam sua efetividade diante das falhas econômicas e oscilações sociais.

Uma das indagações que desponta sobre essa função diante da forte complexidade trazida pelas novas tecnologias é de como compreender e adotar níveis diferenciados e adequados de regulação estatal, gerando graus de intervenção estatal indireta sobre serviços públicos e atividades econômicas.

Ademais, com base nos objetivos e fundamentos da República, quando da edição do Plano Diretor da Reforma do Aparelho do Estado, em 1995, o governo brasileiro apresentou um desenho de governança regulatória próximo ao sistema norteamericano. A ideia era reestruturar a Administração Pública, então organizada pelo Decreto-lei no 200/67 a provado durante o regime militar.

O mestrado em Direito da Regulação visa contribuir para a análise da complexa e efetiva construção de uma nova função regulatória brasileira, que, de um lado, leve em conta a sua própria história, se acople aos seus costumes e observe as suas peculiaridades jurídico-constitucionais. E, sobretudo, seja um instrumento que contribua para o ajuste do curso da governança estatal nos campos econômicos e sociais de forma mais republicana e democrática.

\section{REFERÊNCIAS}

BALDWIN, Robert; CAVE, Martin; LODGE, Martin. Understanding Regulation. Theory, Strategy, and Practice. 2nd. Ed. Oxford: OUP, 2012.

BERNSTEIN, Marver H. Regulating business by independent commission. 2. tir. New Jersey: Princeton University Press, 1955.

CAVALCANTI. Bianor Scelza. O gerente equalizador: estratégias de gestão no setor público. Rio de Janeiro: Editora FGV, 2008.

COSTA, Frederico Lustosa da. Brasil: 200 anos de Estado; 200 anos de administração pública; 200 anos de reformas. Revista de Administração Pública, Rio de Janeiro 42(5):829-74, set/out. 2008.

. Reforma do estado e contexto brasileiro: crítica do paradigma gerencialista. Rio de Janeiro: FGV, 2010. 
EPSTEIN, Richard A. How progressives rewrote the constitution. Cato Institute: Washington, 2001.

EPSTEIN, Richard A. Why the modern administrative state is inconsistent with the rule of law. NYU Journal of Law \& Liberty, v. 3, 2006.

FELLMETH, Robert. The interstate commerce omission. New York: Grossman Publishers, 1970.

KOLKO, Gabriel. Railroads and regulations: 1877 - 1916. New York: The Norton Library, 1965.

MASHAW Jerry. Creating the administrative constitution: the lost one hundred years of American administrative law. New Haven: Yale University Press, 2012.

MATTOS, Paulo. O novo estado regulador no Brasil. São Paulo: Singular, 2006.

MCCRAW, Thomas K., et al. Prophets of regulation: Charles Francis, Adams Louis D. Brandeis, James M. Landis, Alfred E. Kahn. Massachussets: Harvard, 1984.

ROSE-ACKERMAN, Susan. Rethinking the progressive agenda: the reform of the American regulatory state. New York: The Free Press, 1992. 